\title{
Burst Mode Q:switched Laser Pulses for Plasma Excitation in LIBS Analysis
}

\author{
Luis Ponce ${ }^{1}$, Lesther Moreira ${ }^{2}$, Eduardo de Posada ${ }^{1}$, Miguel Arronte ${ }^{1}$, \\ Teresa Flores ${ }^{1}$ and Eugenio Rodriguez ${ }^{1}$ \\ ${ }^{1}$ CICATA-Altamira km 14,5 Carretera Tampico Puerto industrial, \\ Altamira 89600, Tamps, \\ 2IMRE-Havana University, Vedado 10400, C. Habana, \\ ${ }^{1}$ México \\ ${ }^{2} \mathrm{Cuba}$
}

\section{Introduction}

The Laser Induced Breakdown Spectroscopy (LIBS), is a technique that has been firmly established for the rapid determination of the elemental composition (Cremers, 2006). It relies on material ablation by using a short duration laser pulse with high density energy enough to produce plasma. By analyzing the light emitted by the plasma, it is possible to determine the elemental composition of practically any material. This technique has significant advantages over other conventional analytical techniques (Cremers, 2007; Rusak et al., 1998; Song et al., 1997). For example, requires no sample preparation, may be performed in solid, liquid or gas phase in samples with any shape or dimension. Moreover, it allows an in-depth study in order to characterize the composition of multi-component material (Adamson et al., 2007; Radziemski et al., 1983). It is especially suitable for field work by offering the possibility of real-time analysis with high portability. Thanks the above mentioned advantages, the LIBS technique has experienced strong growth, which is reflected in a large and growing number of publications.

LIBS is not a new technique: firsts laser-induced breakdown studies go back to the early 1960s and important application studies date from the 1980s with the work of Radziemski (Tognoni et al., 2002). A comprehensive review of LIBS development and applications through the mid-1990s was produced by Rusak et al.(Rusak et al., 1997).

The technique has many attributes that make it an attractive tool for chemical analysis, particularly as regards its potential as a field-portable sensor for geochemical analysis. LIBS is relatively simple and straightforward, so skilled analysts are not required. Little to no sample preparation is required, which eliminates the possibility of adulteration of the sample through improper handling or storage or cross-contamination during sample preparation. LIBS provides a real-time response and simultaneous multi-element detection and analysis. The laser plasma is formed over a very limited spatial area, so that only a very small amount of sample (picograms to nanograms) is engaged in each laser micro-plasma event. All components of the instrument can be made small and rugged for field use and LIBS sensors can be operated either as a point sensor or in a standoff detection mode. The 
detection limits of LIBS are in the low hundreds to tens of ppm range for most common elements, so field-portable LIBS should be capable of field surveying and screening for the geochemical exploration and environmental remediation applications envisaged.

The existing equipment on the market used predominantly solid-state lasers based on Nd:YAG crystals. This is because this type of lasers, in addition to the advantages of robustness and compactness; allow obtaining very short pulses with high power density. To ensure the appropriate parameters, it works in the so-called Q: Switch regime. In this mode of operation, is introduced into the laser cavity an optical shutter based on a crystal whose transmittance is electrically switched, allowing the production of single-pulse of several nanoseconds in duration and very high intensity. In the last years several works have reported an improvement of plasma intensity, and therefore the limits and quality of detection, using systems that generate two consecutive pulses, delivered from one or two synchronized lasers (Tognoni et al., 2002). Recently, it was reported a system with dual crystal modulator by using two LiF crystals (Galbacs et al., 2005). While this system improved the signal-noise relation and the intensity of the plasma emission, has the disadvantage associated with the gradual degradation of these crystals (Zabello et al., 2003). In our study we propose a new low cost LIBS system, which uses passively Q:Switched, capable to produce pulse trains that enhances the plasma intensity. The employment of this regime is illustrated by LIBS characterization of art object. On the other hand, as an example of on-line monitoring of industrial process, and also the possibilities for different pulse regimes, we present the applications of free-running regime in the de-thorning process of cactus, a food Mexican product.

\section{A low cost and portable LIBS device description}

Figure 1 shows an outline of the experimental setup. A Nd:YAG laser emitting at $1064 \mathrm{~nm}$, produces pulses with energy adjustable up to $0.9 \mathrm{~J}$. The active element is a $6 \times 60 \mathrm{~mm}$ Nd:YAG rod, pumped by a xenon lamp. It uses a Q:Switch consisting of a Cr:YAG crystal with $6 \mathrm{~mm}$ in diameter and $3 \mathrm{~mm}$ in thick and initial transmittance of $14 \%$. The light emitted by laser is focused through a $5 \mathrm{~mm}$ focal length lens. The distance between the lens and the surface of the sample was $8.5 \mathrm{~cm}$ to achieve an area of $0.19 \mathrm{~cm}^{2}$. For the experimental conditions used, this means a yield of $4.7 \mathrm{~J} / \mathrm{cm}^{2}$. The sample is placed on metallic base ensuring that the sample surface is located at the focal point.

An optical system coupled with the entry of optical quartz fiber, whose entry can be moved respect to the sample surface. By this way it is possible to capture the emission from a specific region of the plasma.

The spectrometer used in our configuration was an USB4000 Ocean Optics, with $350 \mathrm{~nm}$ to $900 \mathrm{~nm}$ spectral range and $0.2 \mathrm{~nm}$ resolution. The spectra were processed in computer by using Spectra Suite software.

\subsection{Nd:YAG laser with passive Q:Switch}

In the laser head of our device the pump radiation is produced by xenon pulse lamp. The light from this lamp is concentrated on the active medium of Nd:YAG through an special reflector made from monolithic quartz with external metallic coating. The quartz block is doped with atomic Ce at $1 \%$ doping level. This feature avoids the optical damage of the active medium due the ultraviolet light emitted by xenon lamp. On the other hand, the 
conversion of UV to visible radiation contributes to enhance the absorption of pump light in laser crystal and, in consequence, the laser efficiency.

For obtaining a compact device, the resonator mirrors of $99,8 \%$ and $50 \%$ reflectance respectively, were placed at $1.5 \mathrm{~cm}$ form the rod ends. The rod dimensions are $5 \times 50 \mathrm{~mm}$. As a Q:Switch element a YAG:Cr crystal with dimensions $6 \mathrm{~mm}$ in diameter and $3 \mathrm{~mm}$ thick was used. The initial transmittance of Q:Switch was $21 \%$ for $1064 \mathrm{~nm}$ wavelength.

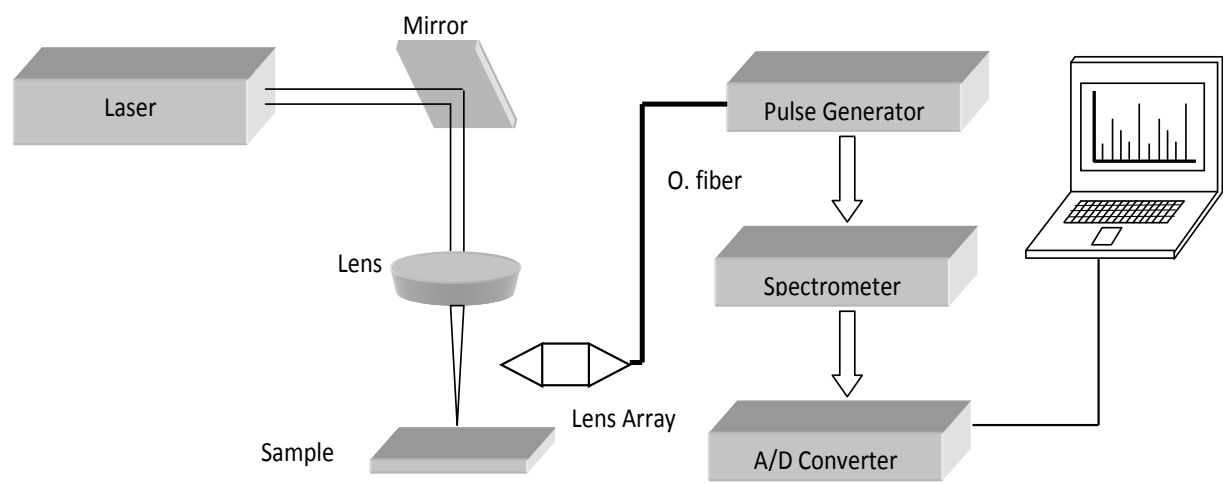

Fig. 1. Schematic of experimental setup

For this configuration, the laser can produce a train of pulses with duration for each pulse of about $20 \mathrm{~ns}$, separated by $10 \mu$ s interval, with a total duration of the pulse train about $700 \mu \mathrm{s}$. In Figure 2 the acquired signal of laser pulse for passive Q:Switched laser is showed.

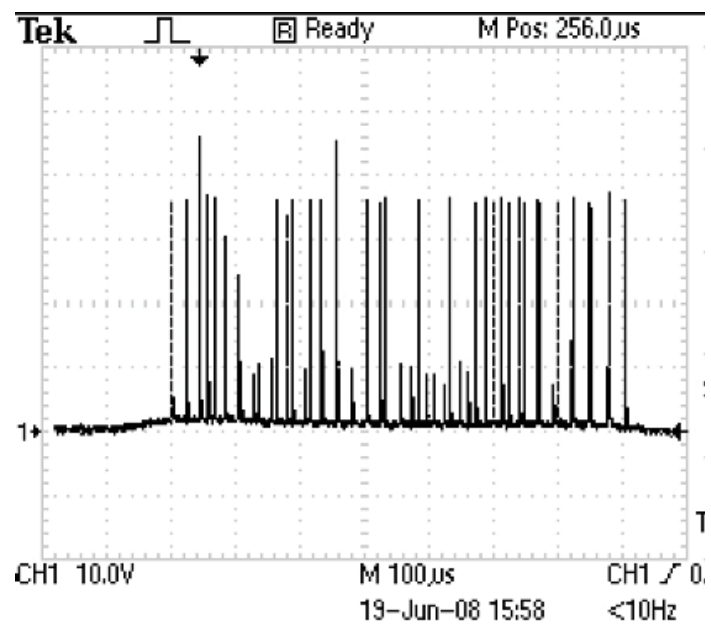

Fig. 2. Oscilogramme of pulse train obtained with passive Q:Switch.

All system elements are mounted on a stereo-microscope in order to obtain better facility for positioning and observation of samples as well as to follow the results of irradiation. The dimensions and weight of LIBS device is $40 \times 20 \times 15 \mathrm{~cm}$ and $5 \mathrm{~kg}$ respectively. Figure 3 shows a photograph of device, called MicroLIBS. 


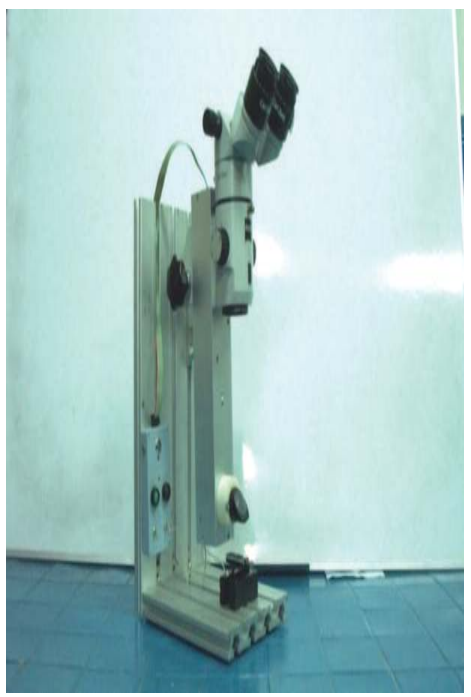

Fig. 3. Photograph of MicroLIBS system.

\section{Results and discussion}

The use of LIBS as an analytical tool depends on three underlying assumptions: (i) that material ablation is stoichiometric so that the composition of the plasma generated is fully representative of the sample composition; (ii) that an optically thin plasma is generated so that emission from the central high-temperature portion of the plasma plume is not reabsorbed in the colder plasma boundary region; and (iii) the plasma is in local thermodynamic equilibrium. These conditions have been verified by Chan \& Russo (Chan \& Russo, 1991) and Corsi et al. (Corsi et al., 2000) and it is understood how to realize these conditions analytically. The use of LIBS for elemental detection is simple and readily accomplished via peak matching against a spectral library constructed in advance for a specific application. For this type of application, which can be accomplished through statistical analysis of LIBS spectra (Anzano et al., 2000), it is only relative peak intensities and overall spectral shape that is important, not absolute peak intensities. Quantitative LIBS analysis of specific elements in natural materials is significantly more difficult because of the broad issue known as "matrix effects". This is an observed dependence of the intensity of the LIBS emission response to the nature of the material analysed (Eppler et al., 1996), which manifests as variations in laser-target coupling and resultant plasma intensity variations. These two facets of the sample, which are generally lumped together as "matrix effects"(Aguilera et al., 2009; Corsi et al., 2000; Ctvrtnickova et al.; Lu et al., 2010; Ma et al.; Mohamed, 2008; Shen et al., 2009; Windom \& Hahn, 2009), will determine LIBS signal reproducibility, namely sample composition and sample surface character.

\subsection{Multi-pulse excitation}

An important approach for enhance the detection limits and the signal-noise relation was reported early (Ponce et al., 2008), and consist in the use of passively Q:Switched multipulse scheme in order to perform the plasma formation-excitation process. In order to 
establish a comparison, it was used an electro-optically Q:Switched Nd:YAG laser with similar parameters with the passively Q:Switched laboratory-made device. In the first case, the laser pulse energy of $0.14 \mathrm{~J}$ was focused on an area of $1 \mathrm{~mm}$ diameter, thus obtaining a fluency of $4.6 \mathrm{~J} / \mathrm{cm}^{2}$, similar to that used in the passively Q:Switched laser. The only experimental difference: Pulse duration of $20 \mathrm{~ns}$ in single pulse configuration and $700 \mu \mathrm{s}$ total duration for the multi-pulse configuration. In Figure 4 are observed an example of spectra captured for both lasers. The spectra chosen to illustrate the comparison were collected form Prickly Pears spines. As can be seen, are clearly identified several peaks associated with the CaII, MgII and CI. These peaks, like the rest of the spectrum, have higher intensity and better signal-noise relation for a train of pulses configuration.

These results can be explained through a several steps process (Zabello et al., 2003). Initially, the absorption occurs in the first laser pulse at the sample surface, with the consequent overheating above the melting point. This causes the explosive material ablation, his rupture and rapid heating of the surrounding atmosphere, and a strong electronic emission. The steam flow expands and produces a shock wave, which in its motion dragging behind an area of low pressure. The initial pressure is restored after about $100 \mu$ s, as estimated experimentally (Kabashin et al., 1990).

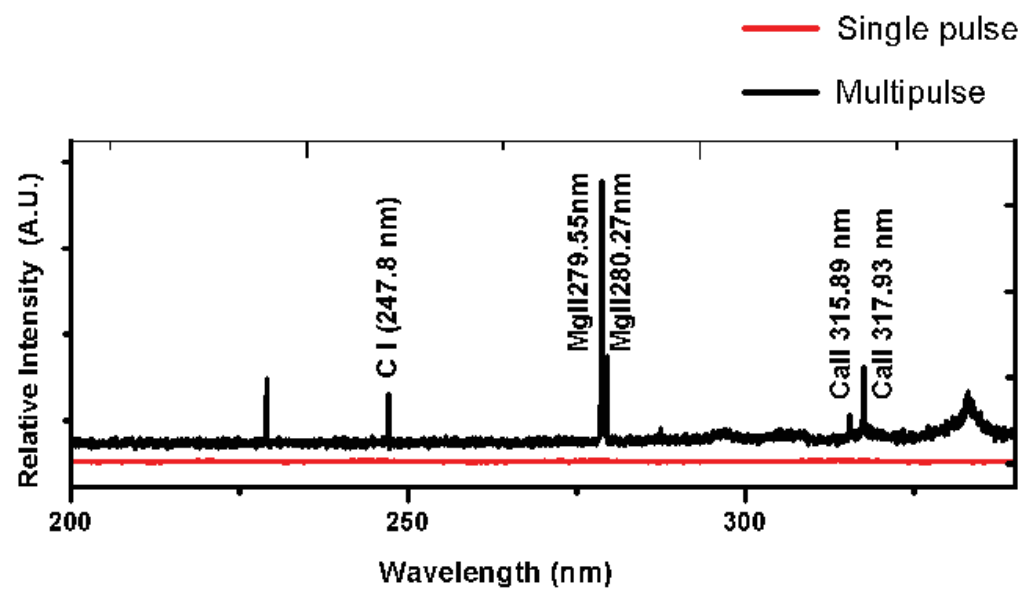

Fig. 4. LIBS spectra captured by using multipulse (above) and single-pulse (below) configurations.

By influencing subsequent pulses, separated from each other by a few tens of microseconds, the conditions for these interactions are the same as the first except for the presence of the above mentioned area of low pressure and a broadcast electronics (noise), much lower, because at that time the flow of electrons has disappeared. Moreover, the highest line intensity for multipulse regime can be explained by the additional excitation pulses produced in the steam of initially ejected material. Thus, the use of pulse trains by using passive Q:Switch, produce higher emission intensities and betters signal noise rate.

\subsection{Free-running excitation}

Typically, the LIBS technique is performed using Q:Switched lasers with high power pulses (megawatt range), produced with time durations in nanosecond range. As far as we know, 
no LIBS experiments were performed by using free-running regime until the recent reports of LIBS in Prickly Pear (Flores et al., 2009), because the low energy density for this mode of laser operation. However, in the mentioned report, due to the strong absorption in areoles, an intense plasma emission takes place even for microsecond range in pulse duration with kilowatts $/ \mathrm{cm}^{2}$ range of laser fluency. As we demonstrated, this allows to use in experiments not only a Q:Switched laser but also a free running low cost Nd:YAG laser regime. The experiments in free-running regime have a great practical interest because at this regime is possible to obtain a higher productivity in spines elimination. On the other hand, the laser operating at this regime is less expensive and the operation cost is lower.

At present, our research group is working of high energy and long pulse LIBS excitation, performed at millisecond pulse time duration. The special interest of this exotic conditions in plasma generation, is explained by two reasons: The possibility of simulation of some natural events like interstellar jets or atmospheric thunders from one side, and, the on-line monitoring of several industrial applications in millisecond range as hole perforation or pulse welding from the other side.

In principle, as lower pulse duration them better resolution can be obtained, if we taking in to account the fact that typically with shorter pulse duration avoid higher power densities and better plasma ionization level. I also important the fact that the plasma life is extended no more than several microseconds, and, in consequence, if the pulse duration is longer, them the interaction with subsequent excitation must be taken in consideration in the LIBS spectra interpretation. As an example of line-width behaviour for different pulse duration, LIBS spectra captured on metal sample are showed in figure 5.

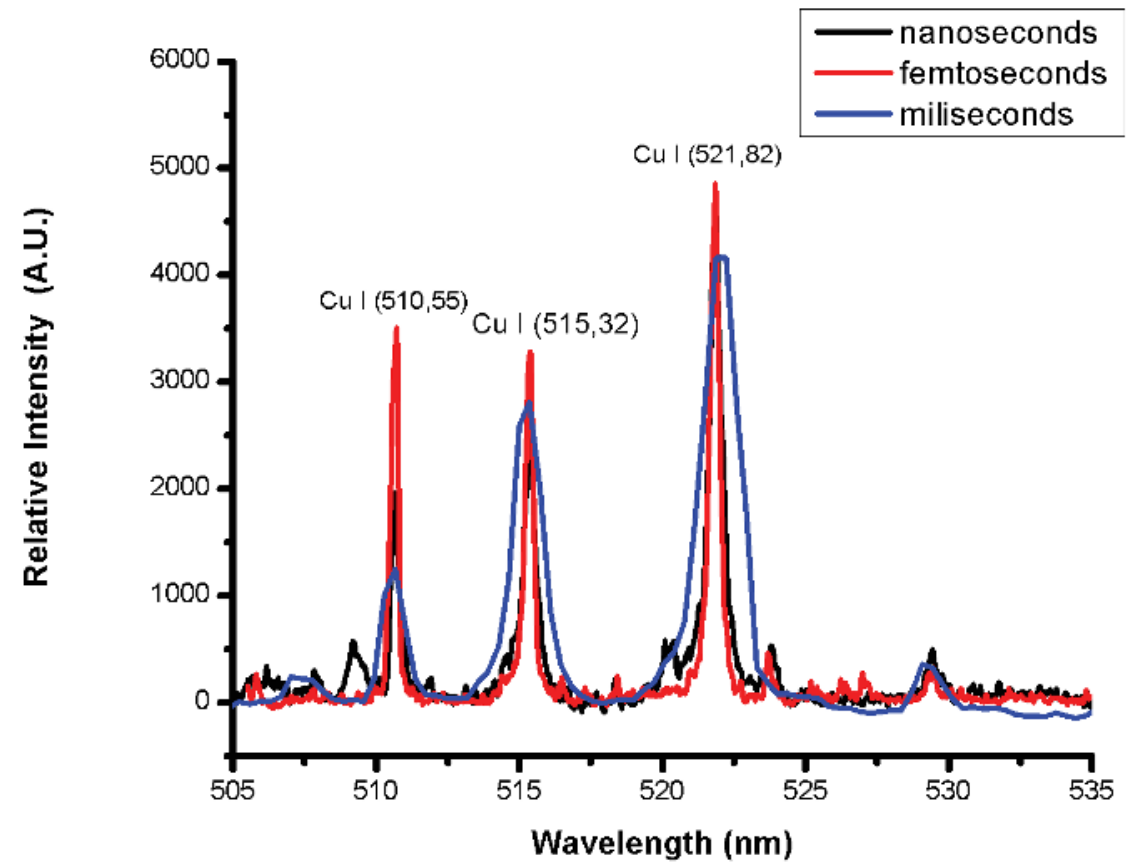

Fig. 5. LIBS spectra obtained from Cu sample. 


\subsection{Field applications: Free-running excitation for Cactus de-thorning}

An exciting example of our LIBS device is the on-line elemental determination for laser dethorning process. In this new application a Nd:YAG (Flores et al., 2009) laser is used for selective ablation of thorns of cactus called opuntia. In figure 6, is showed a deep-profile LIBS measurement of thorn-cortex systems illustrating the behavior of $\mathrm{Na}(\mathrm{I}) 589.5 \mathrm{~nm}$ line and $\mathrm{C}-\mathrm{H}$ band.

These curves shows that LIBS technique contribute to control the spine elimination process: For $\mathrm{C}-\mathrm{H}$ line the relative intensity reach the maximal value after two or three pulses and decrease gradually until the full thorn elimination reaching in this moment a fixed value that correspond to lower percent of $\mathrm{C}-\mathrm{H}$ concentration in cortex. In opposite direction, the $\mathrm{Na}$ line intensity grows gradually reaching a higher level simultaneously with $\mathrm{C}-\mathrm{H}$ decrease. The high concentration of $\mathrm{Na}$ in cortex is reached after spine elimination precisely when the inner part of cactus is to be ablated.

On the other hand, it is another important difference between the two curves showed in figure 6. While the Na pike dependence versus number of pulses growth continuously, the $\mathrm{C}-\mathrm{H}$ dependence shows periodical changes. It's remarkable that similar variations were detected in previous work (Arronte et al., 2010), by photo-acoustic technique when the signal intensity versus number of pulses was measured. In principle, these changes can be attributed to periodical character of combustion process in laser de-thorning, consisting in

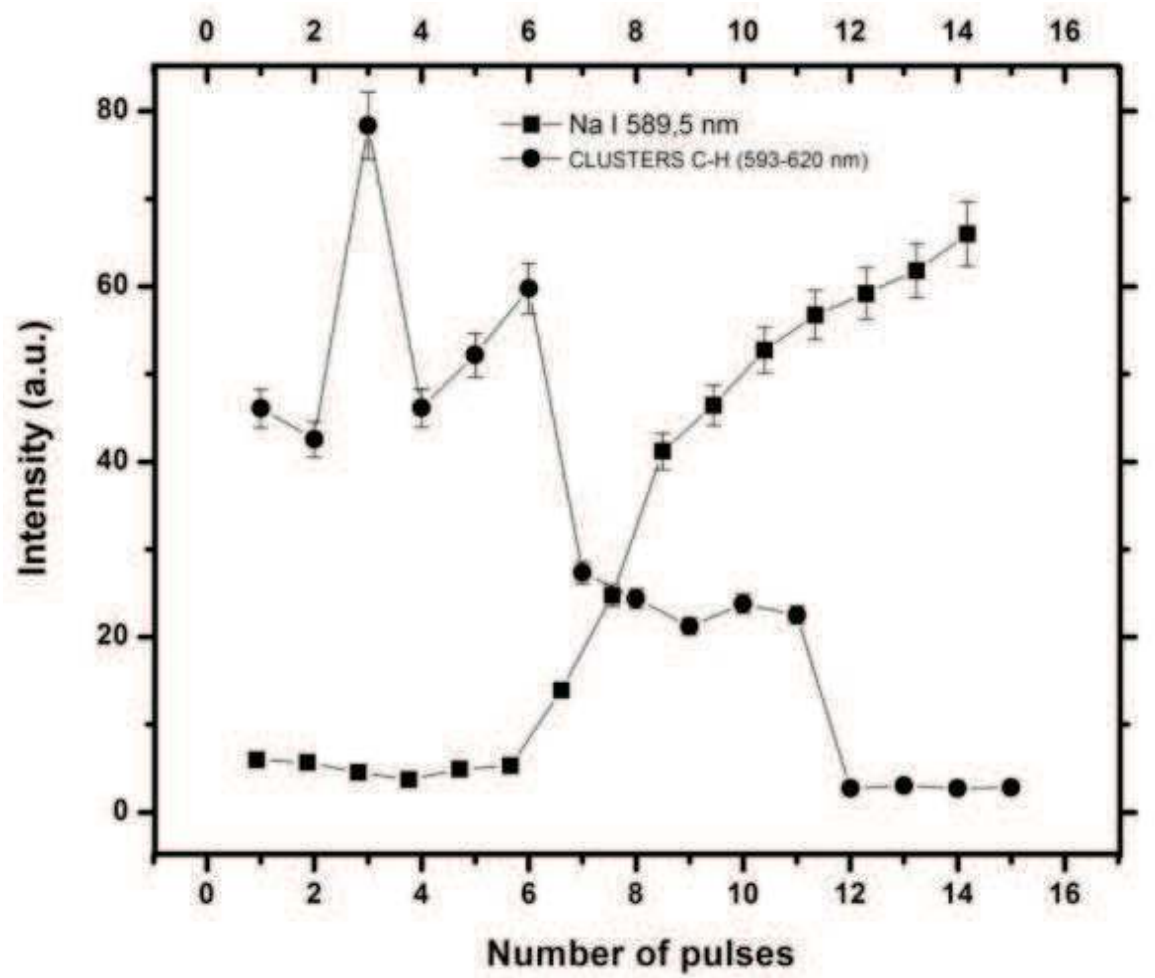

Fig. 6. Intensity profile curves $\mathrm{Na}$ I $(589.5 \mathrm{~nm})$ y emission band of the C-H clusters 
several stages combustion-ablation: While the first pulse prepare the surface making it darker by combustion, the second pulse irradiate a surface with strong absorption and ablate it at very high rate.

\subsection{Field applications: Bust mode Q:Switched excitation for LIBS analysis of art metal object}

LIBS offers a potential alternative to other techniques used in art conservation, works of art, archaeology, etc., being a rapid elemental analysis technique, performed in situ and virtually non-destructive (Fotakis 2006). A LIBS's particularly interesting application is the analysis of metal objects with different compositional layers, particularly when trying to get in-depth composition profiles to distinguish the different elements present in a metal object and can develop a proper restoration process, among other uses, see Fig. 7a. Thus, the determination of the elemental composition, so far unknown, of the different layers present in a 20th Century Metal Jug, of Japanese origin, belonging to a private collection and the only one of its kind (see Figure $7 \mathrm{~b}$ ), is performed using a prototype LIBS equipment. For this purpose, successive burst mode laser pulses are applied to a well-localized area of the sample. The determination of the components avoid to the better selection of the restoration method to be used.

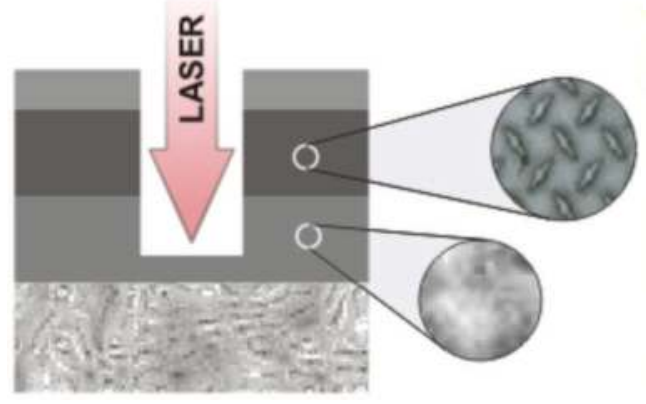

(a)

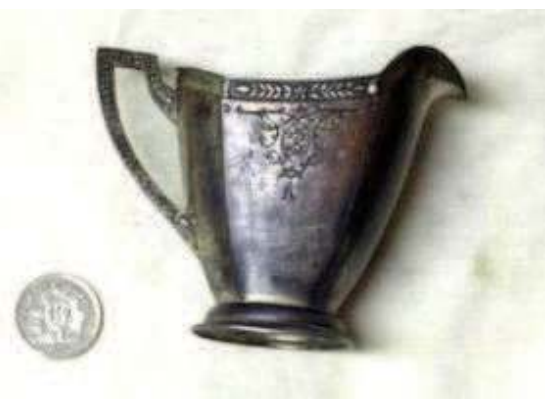

(b)

Fig. 7. (a) An schematic of in-depth laser microanalysis performed by LIBS technique, (b) The picture of Japanese Jug.

A wide spectral window was selected, covering approximately $450 \mathrm{~nm}$ and that was centered at $575 \mathrm{~nm}$, so that any elements contained in the metal object, including those elements that can arise by the influence of environmental factors such as $\mathrm{Ca}, \mathrm{Mg}, \mathrm{Si}, \mathrm{Al}, \mathrm{Na}$ and $\mathrm{K}$, may be measured simultaneously.

The Jug was analyzed superficially in four different and distant points to determine the surface composition and ensure the minimum possible sampling and thereby minimize damage as a result of ablation. The normalized characteristic spectrum for each of the samples is shown in the Figure 8. As shown, certain elements are represented in each of the measurements performed. The $\mathrm{Cu}$ constitutes the fundamental component and in turn the one that shows major proportion in relation to the other materials. Other elements were found to a lesser extent such as $\mathrm{Ca}, \mathrm{Si}, \mathrm{Na}$ and $\mathrm{K}$, including marked relative differences between their intensities, showing changes in their proportions. These elements are attributed to deposition of dirt and impurities on the surface of the sample. Another element 
determined is the $\mathrm{Pb}$ which, similarly to the other aforementioned elements, has lower intensity values as compared to $\mathrm{Cu}$. Finally, $\mathrm{O}$ and $\mathrm{N}$ were determined essentially using the same behavior in all measurements, and their presence is due to mainly the combustion process during the laser-matter interaction with the atmosphere, among others. Each time a laser pulse is applied on the surface of the Jug, a portion of the material that makes up the surface is removed and plasma is generated. If the laser is applied all the time in one place, it will penetrate the material (see Fig. 7a). In order to obtain the composition profile and identify different elements and layers present in the Jug, a multispectral analysis of the emission of the plasma generated by each laser shot was performed. The procedure to determine each layer consisted of recording pulse-to-pulse variations in the intensity of emission lines characteristics of maximum amplitude of the obtained constituent elements of the surface: Ca (II) $392.83 \mathrm{~nm}, \mathrm{~Pb}$ (I) $405.56 \mathrm{~nm}, \mathrm{Cu}$ (I) $521.24 \mathrm{~nm}, \mathrm{Si}$ (II) $546.04 \mathrm{~nm}, \mathrm{Na}$ (I) $588.67 \mathrm{~nm}$ and $\mathrm{K}$ (I) $765.93 \mathrm{~nm}$. The intensity of these elements depending on the number of pulses is shown in the Fig. 9.

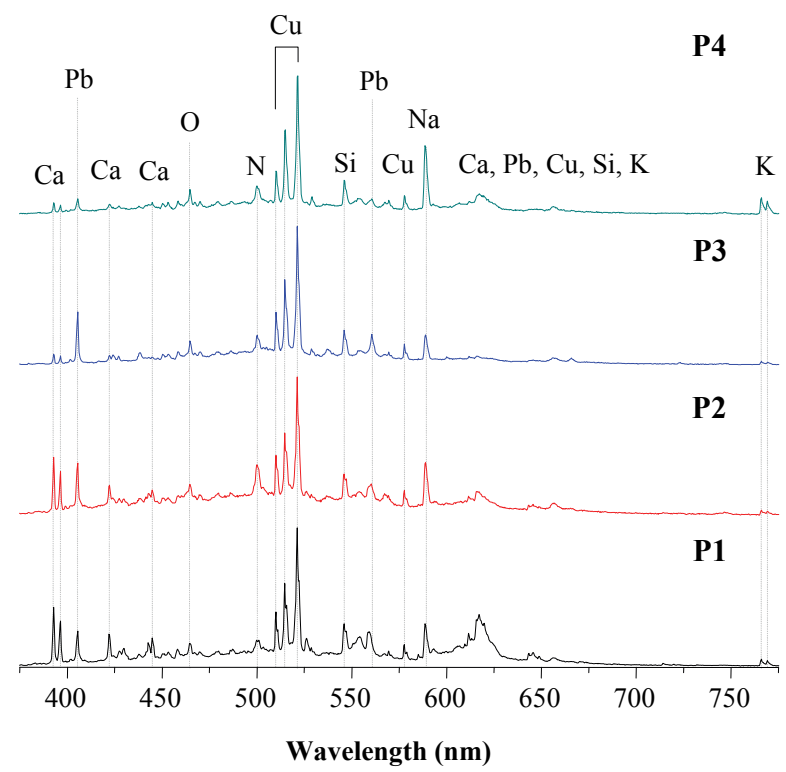

Fig. 8. LIBS spectra obtained in four different zones of metal Jug.

By increasing the number of pulses (greater penetration in the sample), the elements $\mathrm{Ca}, \mathrm{Si}$, $\mathrm{Na}$, and $\mathrm{K}$ had a decreasing behavior. The little variation of intensity from pulse 4 indicates that the elements have virtually disappeared. The lack of a zero value is justified by the presence of background signal, which will have a greater or lesser value depending on the spectral region in which they are found. Low levels in the intensities of these elements, compared to $\mathrm{Cu}$, involve small concentration values in the object. This supports the idea of the presence of elements resulting from the deposition of dirt and impurities on the Jug's surface. Metal objects often show heterogeneity and surface oxidation caused by heat treatment during construction and environmental degradation. These factors can cause variation in the morphology and elemental composition of ancient metal alloys, which results in pollution of surface and global object. 


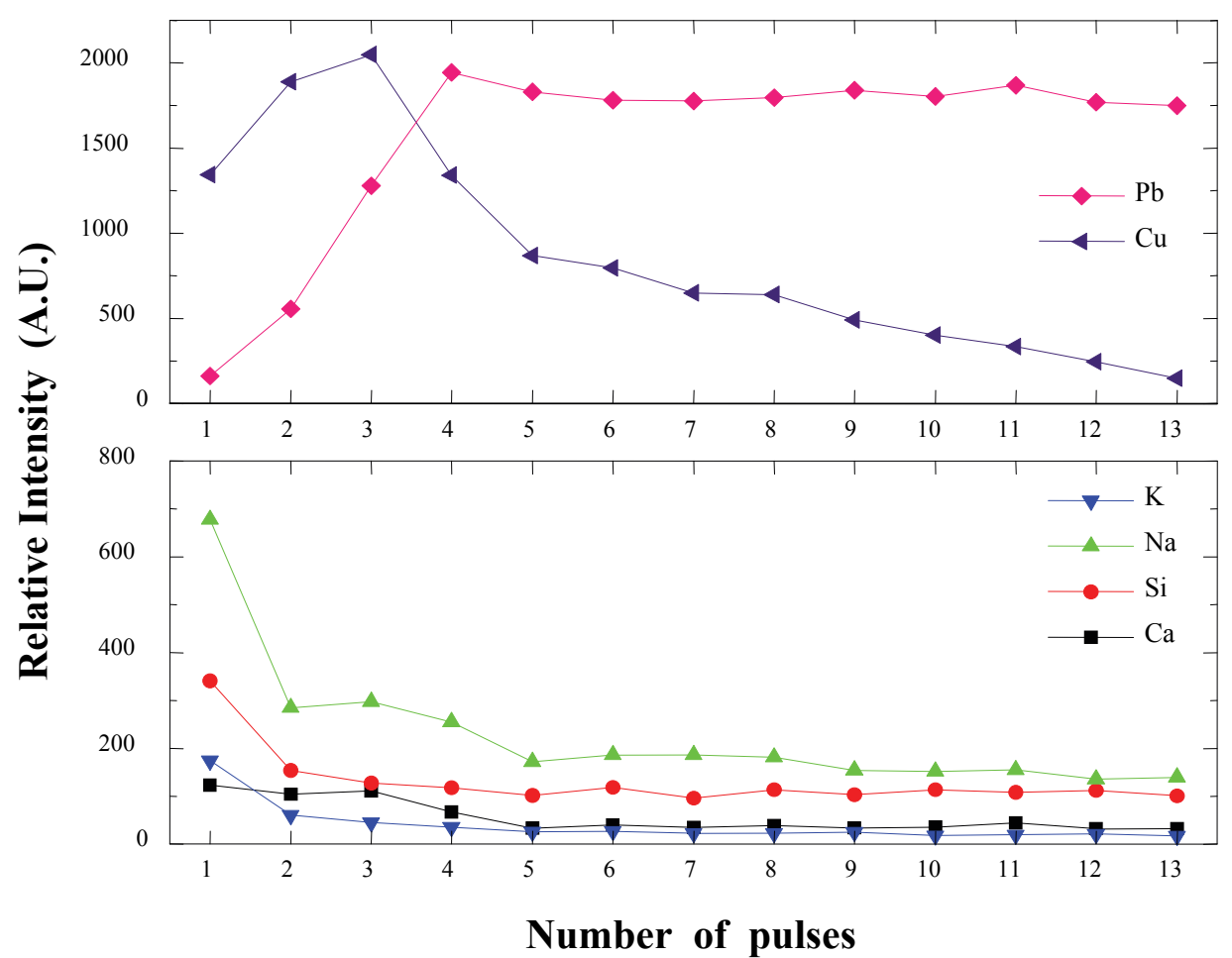

Fig. 9. In-depth profiles for $\mathrm{Ca}(\mathrm{II}) 392.83 \mathrm{~nm}, \mathrm{~Pb}(\mathrm{I}) 405.56 \mathrm{~nm}, \mathrm{Cu}(\mathrm{I}) 521.24 \mathrm{~nm}, \mathrm{Si}(\mathrm{II}) 546.04$ $\mathrm{nm}, \mathrm{Na}(\mathrm{I}) 588.67 \mathrm{~nm}$ and $\mathrm{K}(\mathrm{I}) 765.93 \mathrm{~nm}$ as function of number of pulses.

The $\mathrm{Cu}$, during the first pulses (pulse 1 - pulse 3), shows increasingly higher intensity values, constituting the main element on the jug's surface (pulse 1) and, turn on, a small interior portion of the jug. The $\mathrm{Pb}$, initially (pulse 1) at very small intensity levels, has a linear increase until coming to its maximum value after pulse 4 . After this pulse, the intensity of $\mathrm{Cu}$ starts to decrease until reaching a practically zero value. On the other hand, the $\mathrm{Pb}$ maintains a stable behavior during the following pulses. After pulse 13, virtually all elements have disappeared being the $\mathrm{Pb}$ the majority element in the jug's composition. Figure 10 shows the superposition of the Jug's spectrum, after pulse 13, with a spectrum pattern of $\mathrm{Pb}$ showing a perfect match between these spectrums. It is, therefore, evident the presence of two phases or layers in the Jug: phase 1 with $\mathrm{Cu}$ as the majority element, and phase 2 for $\mathrm{Pb}$.

On the other hand, the $\mathrm{Cu}-\mathrm{Pb}$ interface, through the behavior between the intensity ratios of $\mathrm{Cu} / \mathrm{Pb}$ and $\mathrm{Pb}$, precisely on the pulse 4 is observed clearly in the Figure 11.

Precisely, the $\mathrm{Pb}$ reaches its maximum value and the ratio $\mathrm{Cu} / \mathrm{Pb}$ becomes lesser than 1 which, from the following pulses, tends linearly to zero. While the existence of two layers in the depth profile of the Jug was determined, from Figure 11 can be seen that the Cu layer, in addition to $\mathrm{Ca}, \mathrm{Si}, \mathrm{Na}$ and $\mathrm{K}$, there is the presence of $\mathrm{Pb}$. This result comes from the thickness of $\mathrm{Cu}$ layer and the laser energy. While energy was selected in an optimal work area; nonetheless, given the thickness of $\mathrm{Cu}$ layer, this energy level remains relatively 


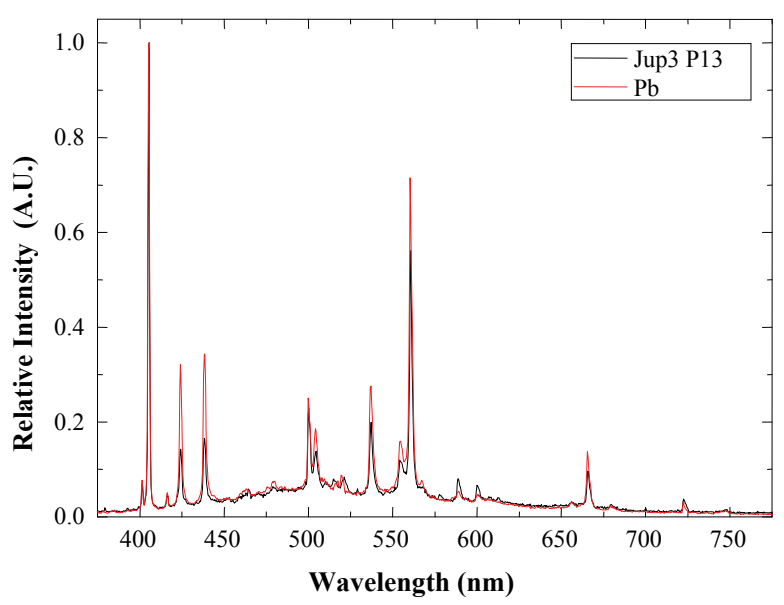

Fig. 10. Comparison between the spectra of metal Jug and $\mathrm{Pb}$ standard.

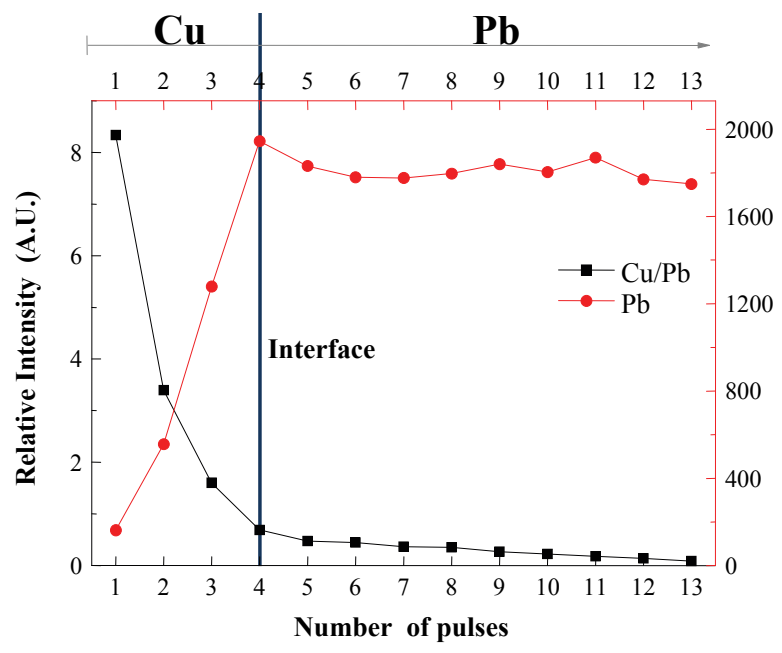

Fig. 11. In-depth behavior of $\mathrm{Cu} / \mathrm{Pb}$ rate and $\mathrm{Pb}$ relative intensity.

sufficient to interact with the next layer $(\mathrm{Pb})$ and generate also laser ablation. Similarly, the presence of $\mathrm{Cu}$ in the $\mathrm{Pb}$ layer can be seen in the Figure 9. In this case, the ratio is given in the form of how laser energy is distributed. The distribution of energy of the pulse laser is not exactly homogeneous (at the edges it is lower than in the center); so the amount of material removed from the irradiated region will be lower in edges than in the center, so that debris of the previous layer may be always remained as it moves in depth. ${ }^{20}$

From the crater produced by 13 laser pulses in interaction with the jug, the crater's wall can be seen, see Figure 12. 


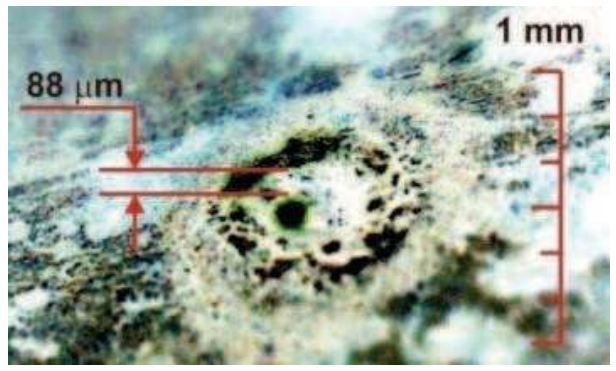

Fig. 12. Contrast image of laser treated zone captured by optical microscopy (magnification 60x).

Referencing the image scale, the approximate depth of the crater can be determined. Therefore, knowing the depth of the crater and the number of pulses, it is possible to determine how much material is extracted in every interaction of laser with the Jug and, in turn, determine the thickness of $\mathrm{Cu}$ layer. Making the necessary calculations, we find that the thickness of the crater's wall is approximately $88 \mu \mathrm{m}$, which implies, for a total of 13 laser pulses, a penetration factor of $6.8 \mu \mathrm{m} /$ pulse. Therefore, as estimated, the thickness of $\mathrm{Cu}$ layer is $27 \mu \mathrm{m}$ knowing that it ends after pulse 4 .

\section{Conclusions}

Recent technological advances are leading to the development of fully field-portable LIBS systems as show MicroLIBS, the compact, portable and low cost LIBS device developed by IMRE-Havana University. The use of Cr:YAG crystal as Q:Switch element allows simplifying the design and reducing costs as compared to electro-optical Q:Switch and also to guarantee more duration that $\mathrm{LiF}$ elements. The application of pulse trains as an excitation source helps to achieve a higher intensity of plasma emission and a substantial improvement in the signal-to-noise ratio compared with single-pulse systems.

The advances in modification of laser parameters open new applications no limited to elemental determination but also covering the laser material processing on-line monitoring or the simulation of specific plasma events in wide range of energies or pulse durations.

Regarding the fields applications, two examples were given: On one side, the real-time monitoring of de-thorning process for one food product, and, on the other side, the compositional characterization of heritage object.

For the first field application, the burst-mode excited LIBS technique is shown to be a suitable method for new industrial processes. Additionally, the approach of complex band emission pattern recognition can be used for determining of contamination problems in such vegetable food.

For the case of metal Jug analysis, the multi-pulse regime shows the possibilities of the technique for heritage objects characterization. The presence of key elements $(\mathrm{Cu}$ and $\mathrm{Pb})$ was determined. They are distributed in layers, being the $\mathrm{Cu}$ the surface element with an estimated thickness of $27 \mathrm{um}$. The elements $\mathrm{Ca}, \mathrm{Si}, \mathrm{Na}$ and $\mathrm{K}$ are impurities caused by dirt and the environment that influence the object's surface.

In resume, the multi-pulse excited LIBS technique serves as an in situ, low-cost and virtually non-destructive analytical tool, in the identification of elements and environmental monitoring or characterizing a wide spectrum of process and objects. 


\section{References}

Adamson, M., Padmanabhan, A., Godfrey, G.J., Rehse, S.J., 2007, Laser-induced breakdown spectroscopy at a water/gas interface: A study of bath gas-dependent molecular species. Spectrochimica Acta Part B: Atomic Spectroscopy 62, 1348-1360.

Aguilera, J.A., Aragón, C., Madurga, V., Manrique, J., 2009, Study of matrix effects in laser induced breakdown spectroscopy on metallic samples using plasma characterization by emission spectroscopy. Spectrochimica Acta - Part B Atomic Spectroscopy 64, 993-998.

Anzano, J.M., Gornushkin, I.B., Smith, B.W., Winefordner, J.D., 2000, Laser-induced plasma spectroscopy for plastic identification. Polymer Engineering and Science 40, 24232429.

Arronte, M., Ortega, E., Ponce, L., de Posada, E., Rodriguez, E., Flores, T., 2010. Real-time monitoring of de-thorning process in Opunctia Nopalea by using a PILA technique. Acoustic Technique 1, 1-10.

Corsi, M., Palleschi, V., Salvetti, A., Tognoni, E., 2000, Making LIBS quantitative: A critical review of the current approaches to the problem. Research Advances in Applied Spectroscopy 1, 41-46.

Cremers, D.A., 2007, Remote Analysis by LIBS: Application to Space Exploration, In: Jagdish, P.S., Surya, N.T. (Eds.) Laser-Induced Breakdown Spectroscopy. Elsevier, Amsterdam, pp. 353-379.

Cremers, L.J.R.a.D.A., 2006, Laser-Induced Breakdown Spectroscopy (LIBS): Fundamentals and Applications.

Ctvrtnickova, T., Mateo, M.P., Yañez, A., Nicolas, G., Laser Induced Breakdown Spectroscopy application for ash characterisation for a coal fired power plant. Spectrochimica Acta - Part B Atomic Spectroscopy.

Chan, W.T., Russo, R.E., 1991, Study of laser-material interactions using inductively coupled plasma-atomic emission spectrometry. Spectrochimica Acta Part B: Atomic Spectroscopy 46, 1471-1486.

Eppler, A.S., Cremers, D.A., Hickmott, D.D., Ferris, M.J., Koskelo, A.C., 1996, Matrix effects in the detection of $\mathrm{Pb}$ and $\mathrm{Ba}$ in soils using laser-induced breakdown spectroscopy. Applied Spectroscopy 50, 1175-1181.

Flores, T., Ponce, L., Arronte, M., de Posada, E., 2009, Free-running and Q:Switched LIBS measurements during the laser ablation of Prickle Pears spines. Optics and Lasers in Engineering 47, 578-583.

Galbacs, G., Budavan, V., Geretovszky, Z., 2005, Multi-pulse laser-induced plasma spectroscopy using a single laser source and a compact spectrometer. Journal of Analytical Atomic Spectrometry 20, 974-980.

Kabashin, A.V., Konov, V.I., Nikitin, P.I., Prokhorov, A.M., Konjević, N., Vikor, L., 1990, Laser-plasma generation of currents along a conductive target. Journal of Applied Physics 68, 3140-3146.

Lu, Y.F., Shen, X.K., Ling, H., 2010. Laser-induced breakdown spectroscopy combined with spatial confinement of plasmas and laser-induced fluorescence for trace-materials detection. In, Shanghai, pp. 697-704.

Ma, Q.L., Motto-Ros, V., Lei, W.Q., Boueri, M., Zheng, L.J., Zeng, H.P., Bar-Matthews, M., Ayalon, A., Panczer, G., Yu, J., Multi-elemental mapping of a speleothem using 
laser-induced breakdown spectroscopy. Spectrochimica Acta - Part B Atomic Spectroscopy.

Mohamed, W.T.Y., 2008, Improved LIBS limit of detection of $\mathrm{Be}, \mathrm{Mg}$, $\mathrm{Si}, \mathrm{Mn}, \mathrm{Fe}$ and $\mathrm{Cu}$ in aluminum alloy samples using a portable Echelle spectrometer with ICCD camera. Optics and Laser Technology 40, 30-38.

Ponce, L., Flores, T., Arronte, M., Hernandez, L.C., Bilmes, G.M., Alvira, F., 2008, Laser Induced Breakdown Spectroscopy widh multi-pulse excitation. Revista Cubana de Física, 25, N2A, pp. 85-87.

Radziemski, L.J., Loree, T.R., Cremers, D.A., Hoffman, N.M., 1983, Time-resolved laserinduced breakdown spectrometry of aerosols. Analytical Chemistry 55, 1246-1252.

Rusak, D.A., Castle, B.C., Smith, B.W., Winefordner, J.D., 1997, Excitational, vibrational, and rotational temperatures in $\mathrm{Nd}$ :YAG and $\mathrm{XeCl}$ Laser-Induced plasmas. Spectrochimica Acta Part B: Atomic Spectroscopy 52, 1929-1935.

Rusak, D.A., Castle, B.C., Smith, B.W., Winefordner, J.D., 1998, Recent trends and the future of laser-induced plasma spectroscopy. TrAC - Trends in Analytical Chemistry 17, 453-461.

Shen, X.K., Ling, H., Lu, Y.F., 2009. Laser-induced breakdown spectroscopy with high detection sensitivity. In, San Jose, CA.

Song, K., Lee, Y.I., Sneddon, J., 1997, Applications of laser-induced breakdown spectrometry. Applied Spectroscopy Reviews 32, 183-235.

Tognoni, E., Palleschi, V., Corsi, M., Cristoforetti, G., 2002, Quantitative micro-analysis by laser-induced breakdown spectroscopy: A review of the experimental approaches. Spectrochimica Acta - Part B Atomic Spectroscopy 57, 1115-1130.

Windom, B.C., Hahn, D.W., 2009, Laser ablation - Laser induced breakdown spectroscopy (LA-LIBS): A means for overcoming matrix effects leading to improved analyte response. Journal of Analytical Atomic Spectrometry 24, 1665-1675.

Zabello, E., Syaber, V., Khizhnyak, A., 2003. Spectral-analytical characteristics of laser plasma under multi-pulse excitation regime. In, pp. 220-222.

Fotakis, C., Lasers in the Preservation of Cultural Heritage; Principles and applications, Institute of Physics Publishing, (New York, 2006). 


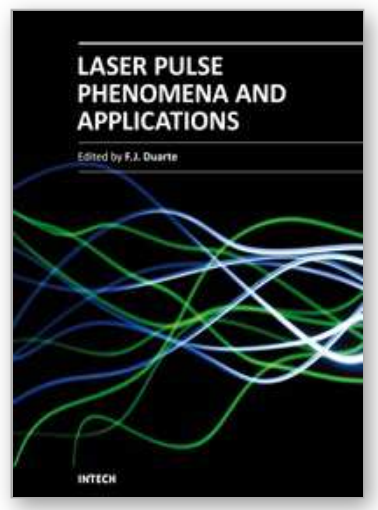

\section{Laser Pulse Phenomena and Applications}

Edited by Dr. F. J. Duarte

ISBN 978-953-307-405-4

Hard cover, 474 pages

Publisher InTech

Published online 30, November, 2010

Published in print edition November, 2010

Pulsed lasers are available in the gas, liquid, and the solid state. These lasers are also enormously versatile in their output characteristics yielding emission from very large energy pulses to very high peak-power pulses.

Pulsed lasers are equally versatile in their spectral characteristics. This volume includes an impressive array of current research on pulsed laser phenomena and applications. Laser Pulse Phenomena and Applications covers a wide range of topics from laser powered orbital launchers, and laser rocket engines, to laser-matter interactions, detector and sensor laser technology, laser ablation, and biological applications.

\section{How to reference}

In order to correctly reference this scholarly work, feel free to copy and paste the following:

Luis Ponce, Lesther Moreira, Eduardo de Posada, Miguel Arronte, Teresa Flores and Eugenio Rodriguez (2010). Burst Mode Q:switched Laser Pulses for Plasma Excitation in LIBS Analysis, Laser Pulse Phenomena and Applications, Dr. F. J. Duarte (Ed.), ISBN: 978-953-307-405-4, InTech, Available from:

http://www.intechopen.com/books/laser-pulse-phenomena-and-applications/burst-mode-q-switched-laserpulses-for-plasma-excitation-in-libs-analysis

\section{INTECH}

open science | open minds

\section{InTech Europe}

University Campus STeP Ri

Slavka Krautzeka 83/A

51000 Rijeka, Croatia

Phone: +385 (51) 770447

Fax: +385 (51) 686166

www.intechopen.com

\section{InTech China}

Unit 405, Office Block, Hotel Equatorial Shanghai

No.65, Yan An Road (West), Shanghai, 200040, China 中国上海市延安西路65号上海国际贵都大饭店办公楼 405 单元

Phone: $+86-21-62489820$

Fax: +86-21-62489821 
(C) 2010 The Author(s). Licensee IntechOpen. This chapter is distributed under the terms of the Creative Commons Attribution-NonCommercialShareAlike-3.0 License, which permits use, distribution and reproduction for non-commercial purposes, provided the original is properly cited and derivative works building on this content are distributed under the same license. 